\title{
BMJ Global Health Just-in-time postnatal education programmes to improve newborn care practices: needs and opportunities in low-resource settings
}

\author{
Laura Subramanian (D) , ${ }^{1}$ Seema Murthy, ${ }^{2}$ Prasad Bogam, ${ }^{2}$ Shirley D Yan, ${ }^{3}$ \\ Megan Marx Delaney, ${ }^{1}$ Christian D G Goodwin, ${ }^{1}$ Lauren Bobanski, ${ }^{1}$ \\ Arjun S Rangarajan, ${ }^{3}$ Anindita Bhowmik, ${ }^{2}$ Sehj Kashyap, ${ }^{4}$ Nikhil Ramnarayan, ${ }^{3}$ \\ Rebecca Hawrusik, ${ }^{1}$ Griffith Bell, ${ }^{1,5}$ Baljit Kaur, ${ }^{6}$ N Rajkumar, ${ }^{7}$ Archana Mishra, ${ }^{8}$ \\ Shahed S Alam, ${ }^{3}$ Katherine E A Semrau (i) ${ }^{1,9}$
}

To cite: Subramanian L, Murthy S, Bogam P, et al. Just-in-time postnatal education programmes to improve newborn care practices: needs and opportunities in low-resource settings. BMJ Global Health 2020;5:e002660. doi:10.1136/ bmjgh-2020-002660

Handling editor Seye Abimbola

- Additional material is published online only. To view please visit the journal online (http://dx.doi.org/10.1136/ bmjgh-2020-002660).

Received 15 April 2020

Revised 3 June 2020

Accepted 15 June 2020
Check for updates

(C) Author(s) (or their employer(s)) 2020. Re-use permitted under CC BY-NC. No commercial re-use. See rights and permissions. Published by BMJ.

For numbered affiliations see end of article.

Correspondence to

Laura Subramanian;

Isubramanian@ariadnelabs.org

\begin{abstract}
Worldwide, many newborns die in the first month of life, with most deaths happening in low/middle-income countries (LMICs). Families' use of evidence-based newborn care practices in the home and timely careseeking for illness can save newborn lives. Postnatal education is an important investment to improve families' use of evidence-based newborn care practices, yet there are gaps in the literature on postnatal education programmes that have been evaluated to date. Recent findings from a $13000+$ person survey in 3 states in India show opportunities for improvement in postnatal education for mothers and families and their use of newborn care practices in the home. Our survey data and the literature suggest the need to incorporate the following strategies into future postnatal education programming: implement structured predischarge education with postdischarge reinforcement, using a multipronged teaching approach to reach whole families with education on multiple newborn care practices. Researchers need to conduct robust evaluation on postnatal education models incorporating these programee elements in the LMIC context, as well as explore whether this type of education model can work for other health areas that are critical for families to survive and thrive.
\end{abstract}

\section{INTRODUCTION}

The global health community has successfully worked to decrease neonatal mortality in the past three decades, ${ }^{1}$ yet 2.5 million newborns still die each year within the first month of life, mostly in low/middle-income countries (LMICs). ${ }^{2}$ Nearly three quarters of newborn deaths happen in the first week of life, so intervening in the first days after birth could save many lives. ${ }^{2}$ Given the short length of stay in facilities after childbirth in LMICs (average 1.5 days for vaginal birth, 4.5 days for caesarean birth), ${ }^{3}$ many newborn

\section{Key questions}

Postnatal education for families is an important investment to improve newborn health in low/middleincome countries (LMICs), but more data are needed on families' current receipt of postnatal education and use of evidence-based newborn care practices in LMICs.

- Recent findings from a $13000+$ person survey in 3 states in India highlight opportunities for improvement in postnatal education for families and use of evidence-based newborn care practices (breast feeding, skin-to-skin care, clean/dry umbilical cord care, hand hygiene) in the home.

- Overall, the literature and our survey data suggest the need to incorporate the following strategies into future postnatal education programming: implement structured predischarge education with postdischarge reinforcement, using a multipronged teaching approach to reach whole families and cover multiple newborn care practices.

- Researchers need to conduct robust evaluation on postnatal education models incorporating these programme elements in the LMIC context, as well as explore whether this type of education model can work for other health areas that are critical for families to survive and thrive.

deaths occur at home. These deaths could be prevented by improving families' use of practices that are shown to reduce newborn illness and death: keeping babies warm through appropriate thermal care (skin-toskin care/kangaroo mother care), early and exclusive breast feeding, infection prevention including handwashing and clean/dry umbilical cord care, and timely recognition of and care seeking for newborn illness. ${ }^{4-9}$ 
Postnatal education for families, defined by Bryanton $e t$ $a l$ as 'structured interventions where parents are provided with education or information related to caring for their newborn ${ }^{10}$ is a key evidence-based strategy to improve newborn care practices and outcomes in LMICs. ${ }^{11}$ These educational interventions are a critical component of postnatal care, and can take multiple forms including provision of information and interactive skills building in newborn care practices. Postnatal education programmes for parents have been shown to reduce newborn illness and death by improving hygienic umbilical cord care, breast feeding and appropriate thermal care..$^{4612-14}$ In a recent scoping review of 77 postnatal education interventions in LMICs, more than half (56\%) of studies reported a positive change in newborn care practices or health outcomes. ${ }^{15}$ Evidence indicates that newborn care counselling/education is more easily improved than other aspects of postnatal health services, ${ }^{16}$ suggesting that it may be a 'low-hanging fruit' to contribute to improved newborn outcomes.

\section{RATES OF POSTNATAL EDUCATION AND NEWBORN CARE PRACTICES IN LMICS \\ Gaps in the evidence base on postnatal education and newborn care practices}

The literature is promising in terms of postnatal education's effects on newborn care practices and outcomes in LMICs. However, there are some gaps in the evidence base that warrant further exploration. Most evaluated programmes had key limitations in topic coverage and target audience. The majority (61\%) of postnatal education programmes in LMICs only cover a single topic, most commonly breast feeding and multitopic programmes also prioritise breast feeding $(50 \%)$ over other topic areas (thermal care $37 \%$, infection prevention $30 \%$, recognition of danger signs $27 \%$, umbilical cord care $13 \%) .{ }^{15} \mathrm{In}$ addition, few evaluated programmes have targeted family members beyond the mother, ${ }^{15}$ despite evidence that other family members (ie, fathers, grandparents) often influence newborn care decisions. ${ }^{141718}$ Consequently, there is a lack of data on the effectiveness of multitopic postnatal education programmes for multiple family members in increasing families' use of a set of newborn care practices.

There is also room for improvement in study size: half of the studies in the scoping review noted above had small sample sizes (fewer than 135 participants), ${ }^{15}$ and a Cochrane review of postnatal education interventions indicated that more large well-designed studies are needed to detect clearer effects on newborn outcomes. ${ }^{10}$ Population-based surveys like the Multiple Indicator Cluster Surveys ${ }^{19}$ and the Demographic and Health Surveys ${ }^{20}$ could potentially offer good measurement opportunities, but these surveys only collect data about receipt of postnatal care services broadly (not postnatal education specifically) and newborn feeding practices (not other newborn care practices). In order to address

\begin{tabular}{|c|c|}
\hline & $\begin{array}{l}N=13730 \\
n(\%)\end{array}$ \\
\hline \multicolumn{2}{|l|}{ Respondent type } \\
\hline Mother & $12863(93.7 \%)$ \\
\hline Family caregiver & $496(3.6 \%)$ \\
\hline Mother + family caregiver & $371(2.7 \%)$ \\
\hline \multicolumn{2}{|l|}{ Maternal characteristics } \\
\hline Maternal age (years; mean (SD)) & $24.2(3.62)$ \\
\hline $\begin{array}{l}\text { Maternal years of schooling } \\
\text { (Mean (SD)) }\end{array}$ & $8.52(3.83)$ \\
\hline Family owns smartphone & $10025(73.0 \%)$ \\
\hline \multicolumn{2}{|l|}{ Birth characteristics } \\
\hline Singleton birth & 13625 (99.2\%) \\
\hline Primiparous & $6305(45.9 \%)$ \\
\hline Caesarean section delivery & $4887(35.6 \%)$ \\
\hline Baby sex: female & $6616(48.2 \%)$ \\
\hline $\begin{array}{l}\text { Birth weight (grams) per } \\
\text { respondent recall or hospital } \\
\text { discharge card (mean (SD)) }\end{array}$ & $2770(533)$ \\
\hline $\begin{array}{l}\text { Sick Newborn Care Unit } \\
\text { admission }\end{array}$ & $2398(17.5 \%)$ \\
\hline $\begin{array}{l}\text { Maternal length of stay (days; } \\
\text { median }(95 \% \mathrm{CI}))\end{array}$ & 2.77 (2.73 to 2.81$)$ \\
\hline
\end{tabular}

these gaps in the evidence base, the global community needs more robust studies in LMICs on postnatal education uptake and newborn care practices in the home.

\section{New data on postnatal education and newborn care practices from large-scale study in India}

Recent evidence from a preintervention survey in India sheds light on the current state of postnatal education in health facilities, as well as families' use of evidence-based newborn care practices in the home. From October 2018 to January 2019, we conducted a phone survey of mothers who had delivered a baby within the past month in three states in India (Punjab, Karnataka and Madhya Pradesh) in order to assess existing postnatal education and newborn care practices prior to implementation of a structured postnatal education intervention at scale. We identified 24 district-level hospitals for the study by randomly selecting high and low delivery-load hospitals from the universe of 91 district hospitals in the three states. As part of a larger study, we calculated respondent sample sizes to produce facility-level estimates. Trained investigators collected phone numbers from 18557 mothers who delivered at the study hospitals, and successfully contacted 14219 mothers/family caregivers (77\% response rate) by phone at 4 weeks post delivery to administer a quantitative survey. Thirteen thousand seven hundred and thirty respondents completed the survey (excluding 489 families with a neonatal or maternal death). Investigators used a structured questionnaire to 
Table 2 Receipt of in-hospital postnatal education and topics taught

$\mathrm{N}=13730$

n (\%)

\begin{tabular}{|c|c|}
\hline $\begin{array}{l}\text { Received in-hospital postnatal education } \\
\text { care* }^{*}\end{array}$ & \\
\hline Yes & $6120(44.6)$ \\
\hline No & $7610(55.4)$ \\
\hline Type of in-hospital postnatal education rec & ived $^{*}$ \\
\hline Predischarge group education & $2446(17.8)$ \\
\hline Predischarge bedside education & $3042(22.2)$ \\
\hline Discharge education & $1168(8.5)$ \\
\hline Other education & $56(0.4)$ \\
\hline Topics taught (based on recall) * & \\
\hline Exclusive breast feeding & $3592(26.2)$ \\
\hline How to keep the baby clean & $1312(9.6)$ \\
\hline Keeping the baby warm & $780(5.7)$ \\
\hline Handwashing & $484(3.5)$ \\
\hline Warning signs of newborn illness & $442(3.2)$ \\
\hline Skin-to-skin care & $258(1.9)$ \\
\hline Not applying anything on umbilical cord & $42(0.3)$ \\
\hline Other & $818(6.0)$ \\
\hline Do not know & $424(3.1)$ \\
\hline $\begin{array}{l}\text { Received postdischarge health messages } \\
\text { or videos on smartphone }\end{array}$ & $217(1.6)$ \\
\hline
\end{tabular}

${ }^{*}$ Among all respondents. Respondents could report multiple types of postdelivery education received and multiple topics taught, with some overlap expected in similar topics (ie, keeping the baby warm, skin-to-skin care).

ask respondents about demographic and birth characteristics, receipt of postnatal care education, newborn care practices, postdischarge complications and hospital readmissions. All participants provided verbal informed consent at the time of the follow-up phone survey. There were no funds or time allocated for patient or public involvement, so we were unable to involve patients in study design, outcome development, results interpretation, writing or editing of this document.
Almost all phone surveys were conducted with the mother only, with family caregivers joining a minority of phone calls (table 1). Mothers were in their midtwenties on average, and the majority had a previous child. The study hospitals had typical caesarean section, Sick Newborn Care Unit (SNCU) admission rates and maternal length of stay for district-level hospitals. Demographic and delivery characteristics were similar across states (data not shown).

The survey data show clear gaps in receipt of postnatal education in this preintervention context (existing education offered in the study hospitals prior to a formal postnatal education intervention; table 2). Fewer than half of respondents received any postdelivery education on newborn care before leaving the hospital. Bedside education was the most commonly reported type; fewer respondents received group or discharge education. Recall of specific topics was generally low: one quarter of respondents recalled being taught about exclusive breast feeding, and fewer than $10 \%$ recalled being taught about hand hygiene, keeping babies warm/skin-to-skin care, umbilical cord care or warning signs of newborn illness. Mothers versus other family caregivers had similar recall of topics taught (data not shown). Postdischarge receipt of health messages or videos on smartphones was minimal.

Respondents' use of evidence-based newborn care practices in the home varied widely (table 3 ). More than three quarters of respondents exclusively breast fed their baby in the past 24 hours. Fewer than half of respondents practisced proper umbilical cord care (put nothing on the cord) before the cord fell off. Practice of skin-to-skin care at any time was low, as were hand hygiene practices while feeding the baby or handling baby stool/urine. Newborn care practices were similar across states, with the exception of some variation in cord care practices (data not shown). Respondents who received any postnatal education had slightly higher rates of newborn care practices (with the exception of breast feeding; table 3), and rates of evidence-based practices varied slightly by type of education received (online supplementary table 1). Respondents who received topic-specific education on cord care, skin-to-skin care or handwashing had

Table 3 Respondents' use of evidence-based newborn care practices in the home for the first month of life (reported at 4 weeks post delivery)

\begin{tabular}{|c|c|c|c|c|c|}
\hline & $\begin{array}{l}\text { Baby } \\
\text { exclusively } \\
\text { breast feed in } \\
\text { past } 24 \text { hours } \\
\text { n (\%) }\end{array}$ & $\begin{array}{l}\text { Proper } \\
\text { umbilical cord } \\
\text { care (nothing } \\
\text { on cord) } \\
\mathrm{n}(\%)\end{array}$ & $\begin{array}{l}\text { Ever } \\
\text { practised } \\
\text { skin-to-skin } \\
\text { care } \\
\text { n (\%) }\end{array}$ & $\begin{array}{l}\text { Washes } \\
\text { hands when } \\
\text { feeding } \\
\text { baby* } \\
\text { n (\%) }\end{array}$ & $\begin{array}{l}\text { Washes hands } \\
\text { when handling } \\
\text { baby stool/ } \\
\text { urine* } \\
\mathrm{n}(\%)\end{array}$ \\
\hline All respondents $(n=13730)$ & $10621(77.4)$ & $6334(46.1)$ & $1109(8.1)$ & 2867 (20.9) & $2578(18.8)$ \\
\hline Received any postnatal education $(n=6120)$ & $4764(77.8)$ & $3001(49.0)$ & $699(11.4)$ & $1434(23.4)$ & $1299(21.2)$ \\
\hline No postnatal education $(n=7610)$ & $5857(77.0)$ & $3333(43.8)$ & $410(5.4)$ & $1433(18.8)$ & 1279 (16.8) \\
\hline
\end{tabular}

*Unprompted recall of key moments when respondents wash their hands. 
higher rates of the corresponding newborn care practices (online supplementary table 2).

\section{IMPLICATIONS FOR POSTNATAL EDUCATION PROGRAMMING New study data highlight the need for postnatal education}

Our survey results highlight a clear need for postnatal education aimed at improving families' use of evidencebased newborn care practices. More than half of respondents did not receive any postnatal education in this preintervention setting, and if they did, it was mainly about breast feeding. This is consistent with existing evidence that the majority of postnatal education in LMICs focuses on breast feeding. ${ }^{15}$ The education rate for breast feeding (26\%) is comparable to another study from India, although that study found higher education rates on hygiene and identifying danger signs of illness. ${ }^{21}$ Our survey data show that mothers' use of evidence-based newborn care practices at 4 weeks post delivery is relatively low, with the exception of exclusive breast feeding. The high rate of exclusive breast feeding $(77 \%)$ is consistent with other studies from India at 4 weeks post delivery ${ }^{21-23}$ as well as the India National Family Health Survey 20152016 rate of exclusive breast feeding for babies under 2 months old, ${ }^{24}$ and aligns with our study team's expectations given the country's investments in breastfeeding promotion programmes. The rate of proper umbilical cord care $(46 \%)$ is consistent with a systematic review of cord care practices in LMICs that found widespread traditions of applying substances to the umbilical cord, ${ }^{25}$ and aligns with the study team's experience that clean/ dry cord care is not always discussed in hospital discharge instructions. The low rate of skin-to-skin care $(8 \%)$ likely reflects the fact that relevant healthcare practice guidelines in India focus specifically on kangaroo mother care (a more detailed version of skin-to-skin care for low birth weight and preterm newborns), and those programmes have only recently been introduced in some states. One study in Nepal found a considerably higher rate of skinto-skin care $(70 \%$ in control group at 5-6 weeks post delivery),${ }^{26}$ indicating there may be variation in this practice across regions.

While these survey data are self-reported and from a specific setting in India, the study adds value to the literature by providing a robust dataset (13 000+respondents) on mothers' receipt of postnatal education and use of multiple evidence-based newborn care practices at a key timepoint (the first month of life) in an LMIC setting. We found one other study on postnatal education with a similar sample size, but it only measured breast feeding at 3 months. ${ }^{27}$ We found very few studies measuring multiple newborn care practices in the first month of life, and most had small sample sizes. While we cannot infer causation in our preintervention descriptive study, the slightly higher rates of evidence-based newborn care practices among respondents who received postnatal education indicate its potential benefit. The low rate of respondents receiving postnatal education highlights opportunities for improvement in both the reach and quality of this education. These opportunities may be relevant in similar LMIC settings, given that many parents in LMICs do not receive sufficient education about how to care for their newborns at home or when/how to seek additional care if needed. ${ }^{15}$ While antenatal education can lay the groundwork for improving mothers' knowledge of newborn care practices, ${ }^{28}$ not all mothers or their partners receive this messaging as part of antenatal care. Postnatal education is a key chance to reach families with essential evidence-based newborn care knowledge and skills. The median maternal length of stay of 2.8 days in our study indicates that there is time to approach families with postnatal education interventions, though length of stay may vary across other LMIC settings.

\section{Translating data to action for postnatal education programmes}

While comprehensive evidence-based guidelines exist for postnatal care services in LMICs writ large,${ }^{29} 30$ the global community lacks specific programme guidelines for postnatal education. The literature is not always clear about what postnatal education programmes include, how they are implemented or rates of education uptake,$^{15}$ leaving evidence gaps in how to operationalise programmes. In order to develop evidence-based programme guidelines for postnatal education, researchers need to rigorously evaluate programmes that build on the programmatic gaps identified in our survey data and the literature: (1) implement structured educational interventions as a key strategy for continuity of care from hospital to home, using multipronged teaching strategies; (2) use a familywide education approach involving the various caregivers in a household; (3) cover a variety of evidence-based newborn care practices.

Education as a key strategy in the continuity of newborn care from hospital to home

A recent scoping review suggests that interventions using a combined approach of predischarge education and postdischarge follow-up have been successful in improving newborn care practices and outcomes in LMICs. ${ }^{15}$ Given the global shift towards facility-based childbirth in LMICs, ${ }^{31}{ }^{32}$ the time spent at a facility after birth is a "critical moment' to start newborn care messaging and skills building. This is especially true for families whose only or longest touchpoint with the health system is at delivery ${ }^{1533}$; many families are lost to follow-up after discharge due to access gaps in postnatal care services. ${ }^{34}{ }^{35}$ Our survey shows that over $40 \%$ of mothers already receive some type of postnatal education prior to discharge from a health facility, which provides a foundation to build on, especially in hospitals where patient education infrastructure is already in place. ${ }^{15}$ Questions remain about the most effective ways to implement predischarge education (ie, group vs bedside, prior to or at discharge-our study was not designed to analyse this in detail) - and postdischarge follow-up (at home, clinic visit, via mobile 
phone). Our survey data show particular opportunities for improvement in smartphone messaging- $70 \%$ of families owned a smartphone, yet only $2 \%$ of mothers received postdischarge phone messaging (likely due to lack of existing digital health programmes for postdischarge care-this is not a standard health system practice in India). In addition, we know educational interventions that inform and activate caregivers with practical skills are most effective in improving patient outcomes, ${ }^{36-39}$ but we need more evidence about the right multipronged teaching approaches to convey information (eg, verbal, multimedia, written materials) and build skills (eg, modelling, role playing) in various LMIC settings. ${ }^{15}$

\section{Family-wide education to engage key family decision-makers as} care partners

Our survey data show that postnatal education gaps exist for both mothers and family caregivers $(55 \%$ do not receive any education), and there is considerable room for improvement in newborn care practices that could be done by any family caregiver: skin-to-skin care, clean/dry umbilical cord care, hand hygiene and recognising signs of illness. Mothers are typically the primary caregivers for their newborns, but other family members (ie, fathers, grandparents, other extended family) often influence newborn care decisions, ${ }^{14}{ }^{17}$ so it is to implementers' advantage to include them in postnatal education efforts. ${ }^{15}$ Family members can support mothers to sustain evidence-based newborn care practices, both through their influential role as decision-makers and by serving as newborn caregivers themselves. To reach family caregivers with education efforts, implementers could apply lessons from family-centred care in the sick/ hospitalised newborn context (ie, SNCU/neonatal intensive care unit), in which healthcare is planned around the whole family rather than just an individual child, and providers respect and engage family caregivers as key partners in care. ${ }^{40}$ There is evidence that a familywide education model improves postdischarge caregiver behaviours and reduces patient complications in cardiac care ${ }^{38}$ so implementers could also draw on lessons from this space.

\section{Multiple newborn care topics to fully prepare families}

Our survey data and the literature show that most postnatal education programmes in LMICs focus on breast feeding, often at the expense of other topics. While exclusive breast feeding is a key practice to promote newborn health, education programmes should also cover other evidence-based practices from the WHO's postnatal care guidelines that benefit both preterm/low birth weight ${ }^{41-43}$ and healthy newborns ${ }^{78}$ : infection prevention (including clean/dry umbilical cord care), thermal care, immunisation and recognising and managing illness. ${ }^{29}{ }^{44}$ Questions remain about the best ways to teach these topics in accordance with adult learning principles-for example, by grouping practices that are closely related (skin-to-skin care and breast feeding; cord care and hand hygiene to prevent infection). Educating families to recognise signs of newborn illness and seek care promptly is particularly important, ${ }^{45}$ since short postpartum stays in LMICs $^{3}$ plus variable quality of postpartum care ${ }^{16}{ }^{46}$ may put newborns at risk for illnesses that show symptoms only after returning home. Our survey showed that only $3 \%$ of families recalled being taught about warning signs of newborn illness, indicating substantial room for improvement.

Overall, postnatal education approaches and content need to align with what women say matters most in the postnatal period: achieving confidence and competence as a mother, regaining health and well-being for their baby and themselves, and parenting in their own cultural context. $^{47}$

\section{CONCLUSION}

As the global community continues to work towards achieving the sustainable development goal for neonatal mortality, we need to scale up implementation of evidence-based interventions to reduce newborn deaths at a faster pace. ${ }^{1}$ Postnatal education is a sound strategy as an integral component of postnatal care programmes to provide families with information and skills to care for their newborns in the home, leading to better newborn outcomes. There is a compelling rationale to invest in postnatal care programmes that address existing programmatic gaps by initiating education at the critical moment of predischarge in facilities, using a multipronged education approach to reach whole families about multiple newborn care practices, and reinforcing messages post discharge. However, researchers need to test these programme models on larger, more representative populations and study samples, and carefully document how the educational interventions are implemented, to better understand which programme approaches are most effective.

Ultimately, we envision effective family-wide education programmes for LMICs that could not only improve newborn health but could also be expanded to maternal health (eg, newborn and mother-focused messages in antenatal care; postpartum education on danger signs and self-care for new mothers) and other critical health areas. We hope the evidence base in this area will continue to grow, and with it, the opportunity to help newborns and their families survive and thrive.

\footnotetext{
Author affiliations

${ }^{1}$ Ariadne Labs, Harvard T.H. Chan School of Public Health/Brigham and Women's Hospital, Boston, Massachusetts, USA

${ }^{2}$ Aurora Health Innovations, Bengaluru, India

${ }^{3}$ Noora Health, San Francisco, California, USA

${ }^{4}$ Center for Biomedical Informatics, Stanford University, Stanford, California, USA

${ }^{5}$ Department of Health Policy and Management, Harvard University TH Chan School of Public Health, Boston, Massachusetts, USA

${ }^{6}$ Directorate of Health Services, Punjab, India

${ }^{7}$ Directorate of Health \& Family Welfare Services, Bangalore, Karnataka, India

${ }^{8}$ Directorate of Public Health \& Family Welfare, National Health Mission, Madhya

Pradesh, India
} 
${ }^{9}$ Division of Global Health Equity \& Department of Medicine, Brigham and Women's Hospital, Boston, Massachusetts, USA

Twitter Seema Murthy @noorahealth, Prasad Bogam @noorahealth, Shirley D Yan @noorahealth, Arjun S Rangarajan @noorahealth, Anindita Bhowmik @noorahealth, Nikhil Ramnarayan @noorahealth, Shahed S Alam @noorahealth and Katherine E A Semrau @k_semrau

Acknowledgements We would like to thank the following Noora Health colleagues who supported the development of this manuscript: Abel Desai, Sahana S.D, Pradeep Kumar K, and all others on the Noora Health and Yosaid research and implementation teams who were instrumental in moving this work forward, including data collectors who conducted phone surveys and the programee staff. We thank the following colleagues from Ariadne Labs for their support in reviewing and preparing the manuscript: Ami Karlage, Eliza Fishman, and Bridget Neville. We thank the Government of Punjab, Government of Karnataka, and Government of Madhya Pradesh for partnering with us to enable data collection for the survey and for providing insights on the findings. Most importantly, we thank the families who participated in our survey.

Contributors LS is the corresponding author and the lead writer for the manuscript. All authors helped conceptualise the manuscript, critically reviewed manuscript drafts and approved the final manuscript. LS, KS, SSA, SM, PB, SK and NR contributed to the study design and SSA, SM, PB, SK and NR led the implementation of data collection for this manuscript. CDGG conducted the background literature review for the manuscript with guidance from LS and MMD. $\mathrm{GB}$ and $\mathrm{RH}$ conducted the analyses of the survey data presented in the manuscript.

Funding AL staff was funded by a grant from Noora Health for this work. NH is supported by private philanthropic donors, foundations and corporate giving. Aurora Health Innovations LLP is a client of Noora Health. Aurora Health Innovations was remunerated by Noora Health for research related services rendered towards completion of this manuscript.

Disclaimer No specific grants or funds were expressly provided or tied to the publication or for the data collection of this manuscript.

\section{Patient consent for publication Not required.}

Ethics approval Ethical approval for the study was obtained from investigators' institutions.

Provenance and peer review Not commissioned; externally peer reviewed.

Data availability statement Data are available upon reasonable request. The dataset consists of de-identified participant data including survey responses of mothers who delivered at one of the twenty-four state-run district hospitals during the study period. Data requests may be sent to Dr. Seema Murthy (s.m. seema@gmail.com). Re-use of data requires prior authorization by the appropriate/ designated authorities at State-level Ministries of Health. There is no additional information (e.g. protocols, statistical analyses) publicly available.

Open access This is an open access article distributed in accordance with the Creative Commons Attribution Non Commercial (CC BY-NC 4.0) license, which permits others to distribute, remix, adapt, build upon this work non-commercially, and license their derivative works on different terms, provided the original work is properly cited, appropriate credit is given, any changes made indicated, and the use is non-commercial. See: http://creativecommons.org/licenses/by-nc/4.0/.

\section{ORCID iDs}

Laura Subramanian http://orcid.org/0000-0002-5090-664X

Katherine E A Semrau http://orcid.org/0000-0002-8360-1391

\section{REFERENCES}

1 Hug L, Alexander M, You D, et al. National, regional, and global levels and trends in neonatal mortality between 1990 and 2017, with scenario-based projections to 2030: a systematic analysis. Lancet Glob Health 2019;7:e710-20.

2 United Nations Inter-agency Group for Child Mortality Estimation. Levels \& Trends in Child Mortality, Report 2019, 2019. Available: https://childmortality.org/wp-content/uploads/2019/10/UN-IGMEChild-Mortality-Report-2019.pdf [Accessed 2 Jan 2020].

3 Campbell OMR, Cegolon L, Macleod D, et al. Length of stay after childbirth in 92 countries and associated factors in 30 low- and middle-income countries: compilation of reported data and a crosssectional analysis from nationally representative surveys. PLoS Med 2016;13:e1001972.
4 Hazra A, Atmavilas Y, Hay K, et al. Effects of health behaviour change intervention through women's self-help groups on maternal and newborn health practices and related inequalities in rural india: A quasi-experimental study. EClinicalMedicine.

5 Darmstadt GL, Bhutta ZA, Cousens S, et al. Evidence-based, costeffective interventions: how many newborn babies can we save? Lancet 2005;365:977-88.

6 Prost A, Colbourn T, Seward N, et al. Women's groups practising participatory learning and action to improve maternal and newborn health in low-resource settings: a systematic review and metaanalysis. Lancet 2013;381:1736-46.

7 Pillay T. Parent-carer education: reducing the risks for neonatal and infant mortality. In: Chubarova Al, ed. Neonatal medicine. IntechOpen, 2019.

8 Salam RA, Mansoor T, Mallick D, et al. Essential childbirth and postnatal interventions for improved maternal and neonatal health. Reprod Health 2014;11(Suppl 1):S3.

9 Lawn J, McCarthy B, Rae Ross S. The healthy newborn: a reference manual for program managers. CDC/CARE, 2001.

10 Bryanton J, Beck CT, Montelpare W. Postnatal parental education for optimizing infant general health and parent-infant relationships. Cochrane Database Syst Rev 2013:CD004068.

11 Polomeno V. The polomeno family intervention framework for perinatal education: preparing couples for the transition to parenthood. J Perinat Educ 2000;9:31-48.

12 Darmstadt GL, Walker N, Lawn JE, et al. Saving newborn lives in Asia and Africa: cost and impact of phased scale-up of interventions within the continuum of care. Health Policy Plan 2008;23:101-17.

13 Bang AT, Baitule SB, Reddy HM, et al. Low birth weight and preterm neonates: can they be managed at home by mother and a trained village health worker? J Perinatol 2005;25(Suppl 1):S72-81.

14 Kumar V, Mohanty S, Kumar A, et al. Effect of community-based behaviour change management on neonatal mortality in Shivgarh, Uttar Pradesh, India: a cluster-randomised controlled trial. Lancet 2008;372:1151-62.

15 Dol J, Campbell-Yeo M, Tomblin Murphy G, et al. Parent-targeted postnatal educational interventions in low and middle-income countries: a scoping review and critical analysis. Int J Nurs Stud 2019;94:60-73.

16 Larson E, Mbaruku GM, Cohen J, et al. Did a quality improvement intervention improve quality of maternal health care? Implementation evaluation from a cluster-randomized controlled study. Int J Qual Health Care.

17 Iganus R, Hill Z, Manzi F, et al. Roles and responsibilities in newborn care in four African sites. Trop Med Int Health 2015;20:1258-64.

18 Sarin E, Maria A. Acceptability of a family-centered newborn care model among providers and receivers of care in a public health setting: a qualitative study from India. BMC Health Serv Res 2019;19:184.

19 Surveys - UNICEF MICS. Available: http://mics.unicef.org/surveys [Accessed 17 Jan 2020].

20 The DHS Program. Quality information to plan, monitor and improve population, health, and nutrition programs. Available: https:// dhsprogram.com/ [Accessed 17 Jan 2020]

21 Varghese B, Roy R, Saha S, et al. Fostering maternal and newborn care in India the Yashoda way: does this improve maternal and newborn care practices during institutional delivery? PLoS One 2014;9:e84145.

22 Adhisivam B, Vishnu Bhat B, Poorna R, et al. Postnatal counseling on exclusive breastfeeding using video - experience from a tertiary care teaching hospital, south India. J Matern Fetal Neonatal Med 2017;30:834-8

23 Pereira NMD, Verma RJ, Kabra NS. Postnatal lactational counseling and neonatal weight pattern. Indian Pediatr 2015;52:579-82.

24 International Institute for Population Sciences (IIPS). National family health survey (NFHS-4), 2015-16. International Institute for Population Sciences (IIPS), 2017

25 Coffey PS, Brown SC. Umbilical cord-care practices in low- and middle-income countries: a systematic review. BMC Pregnancy Childbirth 2017;17:68

26 Shrestha S, Adachi K, Petrini MA, et al. Development and evaluation of a newborn care education programme in primiparous mothers in Nepal. Midwifery 2016;42:21-8.

27 Kramer MS, Chalmers B, Hodnett ED, et al. Promotion of breastfeeding intervention trial (PROBIT): a randomized trial in the Republic of Belarus. JAMA 2001;285:413-20.

28 Weiner EA, Billamay S, Partridge JC, et al. Antenatal education for expectant mothers results in sustained improvement in knowledge of newborn care. J Perinatol 2011;31:92-7. 
29 World Health Organization. WHO recommendations on postnatal care of the mother and newborn. Geneva: World Health Organization, 2013.

30 Kearns AD, Caglia JM, Ten Hoope-Bender P, et al. Antenatal and postnatal care: a review of innovative models for improving availability, accessibility, acceptability and quality of services in lowresource settings. BJOG 2016;123:540-8.

31 Sando D, Ratcliffe H, McDonald K, et al. The prevalence of disrespect and abuse during facility-based childbirth in urban Tanzania. BMC Pregnancy Childbirth 2016;16:236.

32 Montagu D, Sudhinaraset M, Diamond-Smith N, et al. Where women go to deliver: understanding the changing landscape of childbirth in Africa and Asia. Health Policy Plan 2017;32:1146-52.

33 McKellar LV, Pincombe Jl, Henderson AM. Insights from Australian parents into educational experiences in the early postnatal period. Midwifery 2006;22:356-64.

34 Amouzou A, Mehra V, Carvajal-Aguirre L, et al. Measuring postnatal care contacts for mothers and newborns: an analysis of data from the MICS and DHS surveys. J Glob Health 2017;7:020502.

35 Langlois Étienne V, Miszkurka M, Zunzunegui MV, et al. Inequities in postnatal care in low- and middle-income countries: a systematic review and meta-analysis. Bull World Health Organ 2015;93:259-70.

36 Fiest KM, Mclntosh CJ, Demiantschuk D, et al. Translating evidence to patient care through caregivers: a systematic review of caregivermediated interventions. BMC Med 2018;16:105

37 Mosen DM, Schmittdiel J, Hibbard J, et al. Is patient activation associated with outcomes of care for adults with chronic conditions? J Ambul Care Manage 2007;30:21-9.

38 Liu J, Alam SS, Guhabiswas R, et al. Impact of a family caregiver training program in Kolkata, India on post-operative health perceptions and outcomes of cardiothoracic surgical patients. J Glob Health Rep 2019;3.

39 Briscoe C, Aboud F. Behaviour change communication targeting four health behaviours in developing countries: a review of change techniques. Soc Sci Med 2012;75:612-21.

40 McCance T, McCormack B, Dewing J. An exploration of personcentredness in practice. Online $\mathrm{J}$ Issues Nurs 2011;16:1.

41 Ahmadi S, Kazemi F, Masoumi SZ, et al. Intervention based on BASNEF model increases exclusive breastfeeding in preterm infants in Iran: a randomized controlled trial. Int Breastfeed J 2016;11:30.

42 Ahmed $\mathrm{AH}$. Breastfeeding preterm infants: an educational program to support mothers of preterm infants in Cairo, Egypt. Pediatr Nurs 2008;34:125-30. 138.

43 Awasthi S, Srivastava NM, Agarwal GG, et al. Effect of behaviour change communication on qualified medical care-seeking for sick neonates among urban poor in Lucknow, Northern India: a before and after intervention study. Trop Med Int Health 2009;14:1199-209.

44 World Health Organization. Postnatal care for mothers and newborns: highlights from the world Health organization 2013 guidelines. Jhpiego: World Health Organization, 2015.

45 Jennings L, Yebadokpo A, Affo J, et al. Use of job AIDS to improve facility-based postnatal counseling and care in rural Benin. Matern Child Health J 2015;19:557-65.

46 Kruk ME, Leslie HH, Verguet S, et al. Quality of basic maternal care functions in health facilities of five African countries: an analysis of national health system surveys. Lancet Glob Health 2016;4:e845-55.

47 Finlayson K, Crossland N, Bonet M, et al. What matters to women in the postnatal period: a meta-synthesis of qualitative studies. PLoS One 2020;15:e0231415 